\title{
A MARGEM DA ANTOLOGIA EM RUY BELO
}

\author{
INACIO, Carolina da Silva ${ }^{1}$
}

RESUMO: O presente artigo propõe uma análise da noção de antologia na obra País Possivel (1974), do poeta português Ruy Belo (1933-1978). Buscou-se investigar em que medida o livro põe em tensão tal categoria, explorando a organização dos poemas no interior do livro e a utilização dos elementos paratextuais que o compõem.

PALAVRAS-CHAVE: Antologia; País Possível; Ruy Belo.

\section{THE MARGIN OF ANTHOLOGY IN RUY BELO}

\begin{abstract}
The present paper proposes an analysis of the notion of anthology in País Possível (1974), by the Portuguese poet Ruy Belo (1933-1978). The objective is to investigate how the book questions this category by exploring the organization of poems within the book and the use of the paratextual elements that compose it.
\end{abstract}

KEYWORDS: Anthology; País Possível; Ruy Belo.

\section{ENTRE PREFÁCIOS E NOTAS: AS MARGENS DA ANTOLOGIA}

Em 1 de maio de 1974, comemorou-se intensamente em todo território nacional português o primeiro Dia do Trabalho em liberdade após quase cinquenta de ditadura salazarista. Longe de seu país ${ }^{2}$, mas sem por isso estar desatento e insensível à situação política de Portugal, Ruy Belo $^{3}$ redige, em Madrid, a 1 de maio de 1973, exatamente um ano antes, a nota introdutória de

\footnotetext{
${ }^{1}$ Mestranda em Literatura Portuguesa pelo Programa de Pós-Graduação em Letras da Universidade Federal Fluminense. E-mail: carolinasilvainacio@yahoo.com.br

${ }^{2}$ Período em que ocupou o cargo de leitor de Português em Madrid, entre os anos de 1971 e 1977.

${ }^{3}$ Poeta, crítico e tradutor nascido em S. João da Ribeira, Portugal, em 1933. Doutorou-se em Direito Canônico na Pontifícia Universidade S. Tomás de Aquino, em Roma. Licenciado em Direito e Filologia Românica pela Universidade de Lisboa, lecionou no ensino secundário e foi leitor de Português na Universidade de Madrid. Faleceu precocemente, em 1978, em virtude de um edema pulmonar. Publicou nove livros de poesia e uma Jangada | nr. 13, jan/jun, 2019 | ISSN 2317-4722 
País Possível, obra organizada pelo próprio poeta e constituída por poemas de conteúdo assumidamente político. No referido escrito, intitulado "Nota do autor", evidencia-se uma tentativa de resguardar esta obra da categorização tradicional de antologia. Veremos que a organização dada por Ruy Belo ao conjunto de poemas que dá corpo ao "novo" livro coloca em tensão tanto a ideia de antologia como a própria noção de livro de poesia, tendo em vista que sua composição parte de uma recolha de poemas já publicados em livros anteriores.

Fugir a categorizações é um gesto autoral muito caro a Ruy Belo. Neste mesmo ano de 1973 em que publicou País Possível, publicou Transporte no tempo, que se inicia com o texto "Breve programa para uma iniciação ao canto", em que diz:

Escrevo como vivo, como amo, destruindo-me. Suicido-me, mas palavras. Violento-me. Altero uma ordem, uma harmonia, uma paz que, mais do que a paz invocada como instrumento de opressão, mais do que a paz dos cemitérios, é a paz, a harmonia das repartições públicas, dos desfiles militares, da concórdia doméstica, das instituições de benemerência. Ao escrever, mato-me e mato. A poesia é um acto de insubordinação a todos os níveis, desde o nível da linguagem como instrumento de comunicação, até ao nível do conformismo, da conivência com a ordem, qualquer ordem estabelecida (BELO, 2014d, p. 15).

Funcionando como uma espécie de nota que se antepõe aos poemas, este texto bem poderia figurar como prefácio às duas obras publicadas pelo autor em 1973, pois o teor metalinguístico utilizado nas apresentações de ambos os livros nos permite estabelecer uma curiosa comunicação entre elas. Na "Nota do autor", o poeta afirma ser País Possível um novo livro e com isso acaba por exprimir sua concepção do que vem a ser o livro de poesia:

Este livro é um livro novo porque um livro de poesia é, afinal, um lugar de convívio, um local onde os poemas reagem uns contra os outros, se

coletânea de ensaios: Aquele Grande Rio Eufrates (1961), O problema da habitação - alguns aspectos (1962), Boca bilíngue (1966), Homem de Palavra[s] (1969), Transporte no tempo (1973), País possível (1973), A margem da alegria (1974), Toda a terra (1976), Despeço-me da terra da alegria (1978) e Na senda da Poesia (1969). 
criticam mutuamente, se transformam uns nos outros (BELO, 2014c, p. 17).

Tal concepção permite identificar no livro de poesia sua particularidade mais fundamental: a arbitrariedade do poema em relação ao livro. Osvaldo Silvestre, em seu primoroso artigo intitulado Back to the future, explora detalhadamente essa relação, mostrando que a condição paradigmática da página do livro de poesia evidencia a autonomia do poema relativamente ao livro. Ou seja, apesar do vínculo sintagmático que os une, o poema se associa a ele de modo autônomo, arbitrário. Para Silvestre, a antologia seria o tipo de livro mais performativo desta característica e, por isso, o mais propriamente poético. Segundo o autor,

[...] a antologia, enquanto gênero essencialmente poético, é aquele tipo de livro que se edifica sobre a autonomização do texto (o poema) em detrimento do livro que inicialmente o integra. A antologia de poemas é um livro que se faz sobre o desfazer de outros livros, e que ao fazê-lo implicitamente relança a diferença específica do livro de poesia como [...] um todo feito de "folhas soltas" (SILVESTRE, 2016, p. 152, grifos meus).

A antologia figura, nesse sentido, como um lugar de performance que possibilita ao autor reencenar tanto sua própria obra como novas expressões de subjetividade por meio desse “desfazer” dos livros publicados e de uma obra já constituída. No limiar da antologia está País Possível. Sua constituição parece ilustrar tanto o caráter essencialmente antológico dos livros de poesia quanto a possibilidade de subversão dessa categoria através de cuidadosas intervenções do autor sobre o texto, tais como a inclusão de um poema inédito e a anteposição de uma nota autoral que aborda o assunto explicitamente.

A partir do diálogo entre as duas notas, é possível considerar País Possível como uma espécie de subversão: uma subversão do autor a si mesmo. A construção deste livro parece encenar um gesto de rasura que altera não só sua tipologia antológica, mas também a própria matéria poética de que é constituído. Trata-se de uma subversão que Ruy Belo realiza em sua própria obra ao dar aos poemas uma nova organização, uma nova vizinhança e, portanto, novas possiblidades de sentido. Além disso, há supressões, emendas e modificações em versos, como 
ocorre notadamente com alguns dos poemas de Boca Bilíngue (1969), por exemplo, que foram incorporados ao livro e de que trataremos mais adiante.

Ao analisar o espólio do autor de Aquele Grande Rio Eufrates, Manaíra Athayde (2015) identificou a epigenesis como um gesto recorrente no processo criativo de Ruy Belo, ilustrando tal procedimento a partir das alterações escritas à mão que o poeta realizou no exemplar de cabeceira de seu primeiro livro publicado. A autora ressalta que a epigenesis, a permanência da gênese de obras já publicadas, nos permite "analisar como o escritor vê o seu próprio percurso, como ele lida com os contrastes e as mudanças em sua obra e em suas perspectivas de mundo" (ATHAYDE, 2016, p. 48). Nesse sentido, País Possível parece simbolizar uma espécie de revisão das obras já publicadas, agora reordenadas e agrupadas sob um mesmo tema. Isso nos leva a conceber o ato antológico de Ruy Belo como uma epigenesis que extrapola os limites da constante gênese de uma mesma obra - como foi o caso de Aquele Grande Rio Eufrates - e que é capaz de produzir, assim, um novo livro, consoante o que o próprio autor muito enfatizou no prefácio citado anteriormente.

Em grande parte dos prefácios que acompanham livros da mais diversa ordem, é muito comum que o prefaciador aproveite este espaço para estabelecer um diálogo aberto com o leitor. Nos livros literários, muitas vezes, este espaço é utilizado por seus autores para exprimirem concepções do que seja o literário, do que seja o poético ou, curiosamente, do que venha a ser um prefácio e quais os seus limites, caminhando, não raro, para um autojulgamento sobre a boa ou má execução da tarefa. Gérard Genette (2015) postula, em Paratextos Editoriais, um conceito fundamental para pensar um dos principais aspectos atinentes à materialidade de uma obra literária, a paratextualidade. Paratexto, diz Genette (2015, p.9), é "aquilo por meio de que um texto se torna livro e se propõe como tal a seus leitores e de maneira mais geral ao público”, referindo-se nomeadamente aos títulos, subtítulos, prefácios, notas de rodapé, epígrafes, dedicatórias, entre outros tipos de indicadores de organização textual que mantém uma relação de continuidade com o texto. O paratexto é, então, um elemento que cerca e prolonga o texto de modo a apresentá-lo, no sentido mais forte do termo, como ressalta Genette, que é torná-lo presente enquanto "coisa no mundo", para retomar as palavras de Osvaldo Silvestre (2016).

No prefácio de Cidadela, de Saint-Exupery, Ruy Belo demonstra partilhar dessa mesma concepção de paratextualidade em relação ao aspecto funcional dos prefácios: 
Só daremos por bem empregadas estas palavras iniciais se elas afinal vierem a facilitar o acesso do leitor a esta Cidadela, de Antoine de SaintExupéry. São tão ingratos os prólogos...Quantos deles não começam e terminam em si próprios, sem darem passagem para a obra (BELO, s/d, p. 9).

Como podemos notar, o autor compreende o prefácio como um elemento que estabelece com o texto uma relação de continuidade e transição. Para Genette, o vínculo entre texto e seus elementos circundantes é não somente de transição, mas também de transação, visto que entre um texto e os seus elementos periféricos há uma transferência mútua de significação. É o que se pode perceber também no prefácio de País Possível: a nota introdutória do autor interage com o conjunto de poemas por ele selecionados de modo a alterar consideravelmente sua recepção por parte do leitor. Independentemente da nota, a categorização do livro como antologia seria, de qualquer modo, problemática e movediça. No entanto, a disposição dos poemas conforme a ordem cronológica dos livros anteriores, somada à coesão temática intencional e à seleção valorativa, aproxima demasiado a feitura desta obra de um gesto antológico, situando País Possível na margem de qualquer classificação imediata.

Ao selecionar na própria obra aquilo que considera digno de repetição, há, antes de mais nada, a administração de um olhar imbuído de juízo de valor. Ainda recorrendo às notas introdutórias de Ruy Belo para nos aproximarmos do modo como o autor enxerga sua produção, lembremo-nos de algumas de suas palavras no prefácio à segunda edição de Aquele Grande Rio Eufrates, de 1972, em que diz: "A minha solidariedade de base com um livro que passei a abominar mal o reli em letra impressa manifesta-se até no facto de consentir na sua reedição [...].” (BELO, 2014a, p. 17). E ainda: “Todo este livro foi escrito num clima a que não só já não tenho acesso hoje em dia como espero não o voltar a ter.” (BELO, 2014a, p. 22) Em toda indispensável explicação, para usar os vocábulos utilizados no próprio título da nota - que se intitula "Explicação que o autor houve por indispensável antepor a esta segunda edição" - o autor afirma reiteradamente que os dez anos que então decorreram da publicação da primeira edição até ali provocaram nele mudanças muito significativas. Consentir na sua reedição seria então um ato admissível somente a partir das ressalvas que o salvaguardam da repetição (reedição) consentida de "um livro cheio de defeitos" (BELO, 2014a, p. 19).

Este primeiro momento da obra de Ruy Belo, compreendido entre os anos 1961, com a publicação de Aquele grande rio Eufrates, e 1962, com O problema da habitação — alguns Jangada | nr. 13, jan/jun, 2019 | ISSN 2317-4722 
aspectos, não é incorporado a País Possível. Uma exclusão que, consideradas as colocações do autor no prefácio da referida edição, dá a ver a utilização de um critério de valor na seleção e edição da coletânea. Trata-se, pois, de uma recusa manifesta primeiramente no prefácio da segunda edição de seu livro de estreia e depois reafirmada na não inclusão em País Possível, coletânea que é uma antologia de acordo com o que abordamos até aqui.

\section{PAÍS POSSÍVEL, TEMA NECESSÁRIO}

No que respeita à configuração formal, País Possível obedece na disposição dos poemas à ordem cronológica de publicação dos livros que o antecedem, excluindo, como acabamos de destacar, os dois primeiros. Apesar disso, a estruturação da coletânea demonstra não estar somente a mero serviço da cronologia. É o que se pode notar quando observamos que alguns poemas oriundos da mesma obra apresentam uma ordem diversa da que estão dispostos no livro de origem. A título de exemplo, os poemas de Homem de palavra[s] recuperam a ordem das seções em que o livro é dividido e, no entanto, estão ordenados de maneira distinta da edição original, o que mostra que há por trás da estrutura um projeto de organização sintagmática do livro.

$\mathrm{Na}$ sequência de poemas "Lugar onde" e "Portugal Futuro", respectivamente, estabelece-se com a nova arrumação um espelhamento entre os títulos, de modo que Portugal apresenta-se como um lugar em que o "onde" está suspenso em uma temporalidade projetada para o futuro. O poema "Lugar onde" demonstra, em oposição ao que o sucede, um tom de imprecisão de lugar, expresso na ausência de nomeação do país "sem olhos e sem boca" (BELO, 2014c, p. 25) de que tratam os versos. Ocorre, assim, com a nova "vizinhança", o preenchimento elucidativo do que antes era a ausência de um nome. Em "Lugar onde" a palavra pátria, que evoca uma entidade abstrata, imaterial e incorpórea - “(pátria, de palavra tem apenas a superfície)" (BELO, 2014c, p. 25) - se opõe ao vocábulo país, "palavra húmida e translúcida/palavra tensa e densa com certa espessura" (BELO, 2014c, p. 25), e, portanto, material, concreta e mais próxima da realidade do homem. E essa oposição torna-se mais perceptível na última estrofe de "Aos homens do cais": "Nenhum passado vale o dia-a-dia/ Sonho só o que vós me consentis/Verdade a que de vós só irradia/ — Portugal não é pátria mas país”. (BELO, 2014c, p. 30) Em País Possível, nenhum passado histórico tem o mesmo valor que o que se vive no tempo presente: um tempo de censura, opressão e privação de direitos, é 
preciso lembrar. Dar nome a este lugar onde nada se vê e nada se diz representa um ato de reação ao silenciamento e à censura em que Portugal havia mergulhado. "O portugal futuro é um país" (BELO, 2014c, p. 27), diz o primeiro verso de “O portugal futuro". Ao contrário da ideia de pátria, que tem seus valores projetados no passado, o Portugal-país projeta-se para o futuro: “portugal será e lá serei feliz” (BELO, 2014c, p. 27). Nos últimos versos, o sujeito lírico lamenta: "Gostaria de ouvir as horas do relógio da matriz/ mas isso era o passado e podia ser duro/ edificar sobre ele o portugal futuro" (BELO, 2014c, p. 27). O relógio, símbolo da contagem do tempo, representa no poema a medição temporal atrelada a um monumento histórico-religioso correspondente ao passado, um passado monumentalizado, usado a serviço do ideário da propaganda nacional de um regime ditatorial, um passado que o poeta não quer.

Em relação à sequência dos poemas, a estrutura do livro, como se pode notar, foi cuidadosamente planeada por Ruy Belo para que, de fato, eles reagissem uns contra os outros, como expressa a nota do autor, e assumissem novas significações. Além disso, suas intervenções na obra feitas a fim de constituir um novo livro parecem ilustrar o propósito de transgredir qualquer tipo de silenciamento estabelecido pelos quase cinquenta anos de regime fascista. Quando comparadas às versões anteriores, as alterações feitas nos poemas de Boca Bilíngue expressam uma tentativa de elucidar ideias que antes estavam obscuras, ou intencionalmente ocultas. Ou seja, as versões de País Possível expressam, por assim dizer, uma maior vontade de pronunciamento declarado dos problemas sociais e políticos de seu tempo. A inclusão, em "Morte ao meio-dia", da estrofe "O português paga calado cada prestação/ Para banhos de sol nem casa se precisa/ E cai-nos sobre os ombros quer a arma quer a sisa/ e o colégio do ódio é a patriótica organização" (BELO, 2014c, p. 21) exemplifica mais uma investida em nomear abertamente a que povo e a que questões se reporta. Outro caso similar ocorre em "Versos do pobre católico". Após o verso "Venho como um gatuno - o que rouba de frente arrisca e puxa a faca" (BELO, 2014c, p. 23), inclui-se outro, de tom explicativo: "não o político o industrial o presidente dos conselhos de administração" (BELO, 2014c, p. 23). As duas emendas revelam o intento do poeta de se expressar nesta obra com mais clareza por meio de poemas que são "uma forma de intervenção, de compromisso, de luta por um mundo melhor [...]" (BELO, 2014c, p. 18).

No que diz respeito ao tema, identifica-se nesta quase antologia alguns tópicos fundamentais que confrontam o sistema de valores ideológicos nacionais insuflados pelo regime totalitarista do Estado Novo português. A exemplo disso, o poema "Soneto 
superdesenvolvido" tematiza a manutenção de uma condição opressora em nome do sentimento, nesse caso, vago e egoísta de caridade:

\author{
É tão suave ter bons sentimentos \\ consola tanto a alma de quem os tem \\ que as boas acções são inesquecíveis momentos \\ e é um prazer fazer bem
}

Por isso no verão se chega a uma esplanada

sabe melhor dar esmola que beber a laranjada

Consola muito mais viver assim no meio de muitos pobres

que conviver com gente a quem não falta nada

E ao fim de tantos anos a dar do que é seu

independentemente da maneira como se alcançou

ainda por cima se tem lugar garantido no céu

gozo acrescido ao muito que se gozou

Teria este (se não tivesse outro sentido)

ser natural de um país subdesenvolvido

(BELO, 2014c, p. 28)

Um dos valores difundidos pela política de exaltação nacional do Estado Novo é o que o historiador Fernando Rosas chama de mito da pobreza honrada:

[...] um país essencial e incontornavelmente pobre devido ao seu destino rural, no qual, como dizia António Ferro, «a ausência de ambições doentias» e disruptoras de promoção social, a conformidade de cada um com o seu destino, o ser pobre mas honrado, pautavam o supremo desiderato salazarista do «viver habitualmente», paradigma da 
felicidade possível. E, portanto, para usar uma expressão do próprio chefe do governo, «uma vocação de pobreza» (ROSAS, 2001, p. 1035).

O poema, por conseguinte, retrata ironicamente a outra face desse princípio moral, nos mostrando que por trás do sentimento vazio de caridade há a conservação desse estado de coisas. Sem a pretensão de estabelecer com o contexto histórico uma correspondência exaustiva da obra, outro ponto relevante que vale destacar diz respeito à atenção dada questão do desinteresse do Estado nas políticas habitacionais naquele momento. No documentário As armas e o povo (1975), longa-metragem que mostra as intensas comemorações populares nas ruas de Portugal no primeiro Dia do Trabalho após a Revolução dos Cravos, é recorrente na fala da parcela economicamente desprivilegiada da população a reivindicação por uma moradia digna. Considerando esse componente histórico, o poema "Oh as casas as casas as casas" representa em País Possível a importância de uma casa em sua dimensão política. As casas de Ruy Belo, "mudas testemunhas da vida" (BELO, 2014c, p. 33) justificam que “[...] exista/ uma palavra como intimidade/ Sem casas não haveria ruas/ as ruas onde passamos pelos outros" (BELO, 2014c, p. 33). Para Hannah Arendt, a política não é intrínseca ao homem individualmente, ela "surge no intra-espaço e se estabelece como relação" entre homens. (ARENDT, 1998, p. 21). Nesse sentido, a privação do direito à moradia, presentificada tematicamente no livro pelo poema, constitui-se como uma privação da participação em mais uma das muitas esferas da vida política.

Em suma, a organização temática de País Possível demonstra uma atenção muito sensível ao sem-número de problemas sociais promovidos pela máquina opressora do regime fascista a que Portugal esteve submetido, dos quais citamos aqui apenas alguns a título de exemplo. No nível da estrutura, o livro mostra, como destacou Osvaldo Silvestre na introdução da reedição de Boca Bilíngue, que em toda a obra de Ruy Belo verifica-se uma preocupação formal muito expressiva no que tange ao livro enquanto estrutura:

Na verdade, todos os livros de Ruy Belo, sem exceção, nos surgem rigorosamente pensados na sua macro-estrutura, não se limitando a ser, como muitas vezes sucede em coletâneas poéticas, reuniões de um certo número de textos dotados de afinidades temáticas mais ou menos evidentes. Dir-se-ia que um certo desinvestimento na forma do poema - sobretudo evidente se comparado com o sucedido em autores 
paradigmáticos do modernismo ou do tardo-modernismo, como os já referidos Carlos de Oliveira e Herberto Helder - é compensado por um redobrado investimento na forma-livro, o qual, diga-se de passagem, justifica plenamente uma reedição de sua obra livro a livro (SILVESTRE, 1997, p. 11).

A configuração da forma-livro na obra beliana é um dos espaços que favorece a movimentação de sentidos e que não se pode negligenciar. Além de valer-se recorrente de elementos paratextuais, como prefácios, notas introdutórias e epígrafes, o autor dedica notável atenção à organização interna do livro, o que permite, como vimos, a edificação de uma obra como País Possível, constituída pela mobilização da matéria poética de livros já publicados. Considerando que no mesmo ano de sua edição havia sido publicado também Transporte no tempo, como já foi dito antes, o gesto de elaboração paralela do livro, com tal tema e nas circunstâncias políticas em que veio a ser publicado, além de demonstrar o comprometimento do autor com os problemas do seu tempo, evidencia que o país imaginado por Ruy Belo era mais que possível, era necessário.

\section{REFERÊNCIAS BIBLIOGRÁFICAS}

ARENDT, Hannah. O que é política?. São Paulo: Bertrand Brasil, 1998.

ATHAYDE, Manaíra Aires. Ruy Belo e o Modernismo brasileiro: Poesia, espólio. 2016. 362 f. Tese (Doutoramento em Materialidades da Literatura) - Universidade de Coimbra, Coimbra, 2016.

BELO, Ruy. Aquele grande rio Eufrates. $1^{\mathrm{a}}$ ed. Rio de Janeiro: 7Letras, 2014a. . Homem de palavra[s]. $1^{\mathrm{a}}$ ed. Rio de Janeiro: 7Letras, $2014 \mathrm{~b}$.

. "Prefácio". In SAINT-EXUPÉRY, Antoine de. Cidadela. Trad. Ruy Belo. Lisboa:

Editorial Aster, s/d.

. País Possível. $1^{\mathrm{a}}$ ed. Rio de Janeiro: 7Letras, 2014c.

Transporte no tempo. $1^{\mathrm{a}}$ ed. Rio de Janeiro: 7Letras, 2014d.

DI LEONE, Luciana. O mínimo e o monumento. Os Versos de circunstância de Carlos Drummond de Andrade. In: SCRAMIM, Susana e DI LEONE, Luciana (orgs). Ler Drummond hoje. São Paulo: Rafael Copetti Editor, 2014.

GENETTE, Gérard. Paratextos Editoriais. São Paulo: Ateliê Editorial, 2009.

ROSAS, Fernando. O salazarismo e o homem novo: ensaio sobre o Estado Novo e a questão do totalitarismo. Análise Social, Lisboa, v. xxxv, nº 157, p. 1031-1054, 2001. 
SILVESTRE, Osvaldo. Back to the future. O livro de poesia como crítica do livro em papel e do e-book. In: PEDROSA, Celia e ALVES, Ida (orgs). Poesia contemporânea: Voz, imagem, materialidades. Belo Horizonte: EdUFMG, 2016.

. "Introdução". In BELO, Ruy. Boca Bilíngue. Lisboa: Editorial Presença, 1997. 